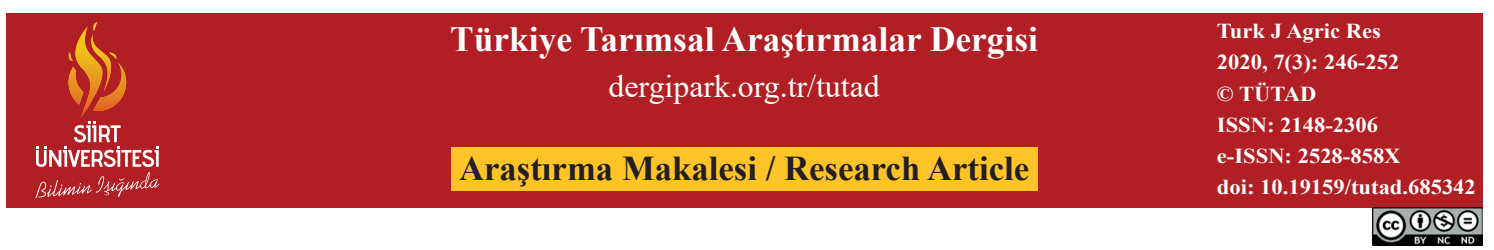

\title{
Dalgacık Bulanık Zaman Serisi Yöntemi ve Gri Tahmin Yöntemi ile Türkiye Buğday Verimi Tahmini
}

\author{
Eyyup Ensar BAŞAKIN*, Ömer EKMEKCİOĞLU, Mehmet ÖZGER, Anıl ÇELİK \\ İstanbul Teknik Üniversitesi, İnşaat Fakültesi, İnşaat Mühendisliği Bölümü, İstanbul, TÜRKIYYE
}

\begin{tabular}{|c|c|}
\hline Geliş Tarihi/Received: 05.02 .2020 & Kabul Tarihi/Accepted: 09.10 .2020 \\
\hline \multicolumn{2}{|l|}{ ORCID ID (Yazar surasuna göre / by author order) } \\
\hline \multicolumn{2}{|c|}{ (1D) orcid.org/0000-0002-9045-5302 (D) orcid.org/0000-0002-7144-2338 (Dorcid.org/0000-0001-9812-9918 } \\
\hline (D) orcid.org/0000-0002-4648-451X & \\
\hline
\end{tabular}

"Sorumlu Yazar/Corresponding Author: basakin@itu.edu.tr

Öz: Bu çalışmada Türkiye'nin 1946-2018 yıllarına ait buğday verim değerlerinin analizi yapılmıştır. Elde edilen 73 yıllık buğday verim değerleri $\left(\mathrm{kg} \mathrm{da}^{-1}\right)$ literatürde son yıllarda sıklıkla kullanılan iki adet matematiksel yöntem ile analiz edilmiştir. Zaman serisi alanında kullanılan Bulanık Zaman Serileri (BZS) ve Gri Tahmin (GT) algoritmaları bu çalışmada kullanılan iki analiz yöntemidir. Ayrıca bu modellere ek olarak zaman serisi önişlem yöntemlerinden olan Ayrık Dalgacık Dönüştürme (ADD) tekniği kullanılarak BZS yöntemi ile hibrit bir model oluşturulmuştur. Analiz aşamasında 53 adet yıllık buğday verim değeri modellerin eğitilmesinde, 20 adet yıllık buğday verim değeri ise modellerin test edilmesinde kullanılmıştır. Modellerin istatistiksel olarak başarılı olup olmadıkları, hata kareleri ortalaması (HKO) ve verimlilik katsayısı (VK) başarı kriterleri ile test edilmiştir. Sonuçlar incelendiğinde, dalgacık bulanık zaman serisi (DBZS) modellerinin en yüksek VK değerine ve en düşük HKO değerine sahip olduğu görülmüştür. Tarım bilimleri alanında ilk kez kullanılan bu yöntem sayesinde daha isabetli kararların alınması öngörülmektedir. Ayrıca çalışma ile, oluşturulan hibrit modelin daha sonra geliştirilmesi adına diğer araştırmacılara 1şık tutacağı düşünülmektedir.

Anahtar Kelimeler: Buğday, verim, bulanık zaman serisi, dalgacık dönüşümü, gri tahmin

\section{Prediction of Turkey Wheat Yield by Wavelet Fuzzy Time Series and Gray Prediction Methods}

Abstract: This study presents the analysis of the wheat yield values for Turkey during the years 1946-2018. The 73-year wheat yield values $\left(\mathrm{kg} \mathrm{da}^{-1}\right)$ were analyzed by two different mathematical methods frequently used in the literature. Fuzzy Time Series (FTS) and Gray Prediction (GP) algorithms used in the time series field are the two analysis methods used in this study. In addition to these models, a hybrid model was created by the FTS method using the discrete wavelet transform (DWT) technique, which is one of the time series pre-processing methods. During the analysis, 53 annual wheat yield values were used to train the models, while 20 annual wheat yield values were used as the test set. Model performances were evaluated with mean square error (MSE) and coefficient of efficiency (CE) success criteria. The results revealed that the wavelet fuzzy time series (WFTS) models had the highest CE value and the lowest MSE value. Thanks to this method, which is used for the first time in the field of agricultural sciences, it is predicted to make more accurate decisions. Besides, it is thought that the hybrid model created with the study will shed light on other researchers for further developments.

Keywords: Wheat, yield, fuzzy time series, wavelet transform, grey prediction

\section{Giriş}

Dünyada tarımı en çok yapılan bitkiler arasında buğday ilk sırada yer almaktadır. Buğday ekmeklik ve makarnalıkolmak üzere iki ana çeşide sahiptir.
Türkiye'de 2018 yılında buğday üretimi; 7.299.270 hektar ekili alanda, yaklaşık 20 milyon ton olarak gerçekleşmiştir (Anonim, 2019a). İnsan 
beslenmesinde çok büyük öneme sahip olan buğdayın, ekim alanları Türkiye'de son yıllarda azalma eğilimindedir. Ekilen alanın azalmasına karşın birim alan başına üretim değeri ise artış eğilimdedir. Verim değerlerinin artmasında; tarım teknolojisinin gelişmesi, buğday genomunda yapılan iyileştirmeler, gübreleme olanaklarının artması ve tarım ilaçlarının kullanımının yardımcı olduğu söylenebilir. Devletlerin ve karar alıcı mekanizmaların, bölgelerinde yaşamakta olan insan sayılarına yetecek kadar buğdayı temin etmek zorundadırlar. Bu temin için kimi zaman depolama yoluna giden yetkili kurumlar, kimi zamanda depo kapasitesinden fazla elde edilen mahsulleri piyasaya sürerek bir denge politikası izlemektedirler. Bu kararların alınmasında geçmiş üretim değerlerine bakılarak gelecekteki değerlerin kestirilmesi büyük önem arz etmektedir. Gerekli aksiyonların hızlı ve doğru bir şekilde alınabilmesi için gelecekte yaşanacak üretim veya verim değerlerinin isabetli şekilde tahmin edilmesi gerekmektedir.

Türkiye'de tarım ürünlerinin fiyat, kalite, miktar veya verim değerlerinin tahmin edilmesi üzerine birçok çalışma mevcuttur. Berk ve Uçum (2019) yaptıkları çalışmada, Türkiye'nin nohut üretimini otoregresif temelli modeller ile tahmin etmeye çalışmışlar; 1985-2018 yılları arasındaki nohut üretim miktarları ile model kuran araştırmacılar, nohut üretim miktarı zaman serisini en iyi temsil eden modeli ARIMA $(1,3,1)$ olarak belirlemişlerdir. Çalışmada tüm değerler eğitim için kullanılmış ve modelin test edilmesi işlemi gerçekleştirilmemiştir. Aynı araştırmacılar, 2019-2023 yıllarında üretilmesi muhtemel nohut değerlerini hesaplamışlardır. Türkiye avokado üretiminin modellendiği bir çalışmada (Akın ve Eyduran, 2017), 1988-2015 yillarında üretilen avokado miktarları ile modelleme yapılarak 2016-2025 yılları için öngörüde bulunulmuş; öngörü modelleri oluşturmak için 3 üstel düzeltme yöntemi kullanılmıştır. Çalışmalarının sonucunda Türkiye avokado üretim zaman serisini en iyi temsil eden yöntemin Brown üstel düzeltme yöntemi olduğunu tespit etmişlerdir. Beş farklı zaman serisi tahmin yöntemi kullanılan başka bir çalışmada ise Altılar ve Terliksiz (2018), Türkiye buğday verim değerlerini tahmin etmişler; araştırmacılar, bir yıl sonraki muhtemel buğday verim değerini en iyi tahmin eden yöntemin çift üstel düzeltme yöntemi olduğunu tespit etmişlerdir. Dünya pamuk fiyatlarını Box-Jenkins yöntemi ile tahmin eden Özer ve İlkdoğan (2013), ARIMA $(1,1,1,)(1,0,1)_{12}$ mevsimsel model ile fiyat tahmini gerçekleştirmişlerdir. Türkiye'de organik incir ihraç fiyatlarını ARMA modeli ile modelleyen Yıldız ve Atış (2019), 2019 ve 2020 yılında ihracat miktarının artacağını, organik incir gerçek fiyatlarının azalacağını öngörmüşlerdir. Literatürden verilen bu örneklerin dikkat çeken ortak özellikleri, modellerin ölçülmüş değerler ile test edilmemesi olarak gösterilebilir. Zaman serisi değerlerinin tümü eğitim olarak alınırsa (zaman serisine bir denklem fit edilirse), tahmin yapılacak yıllarda (gelecekte) nasıl bir performans sergileyeceği bilinemez. Çok başarılı tahmine sahip eğitim modeli test edilecek olursa, düşük başarıda tahminlere yol açtığı görülebilir. Bunun en büyük sebebi ise aşırı öğrenme (aşırı uyum) olarak örnek verilebilir. Bir modelin aşırı eğitiminin önüne geçmek için test kısmında model denklemi doğrulanmalıdır.

Bu çalışmada; Türkiye'de 1946-2018 yılları arasında gerçekleşen buğday verim değerleri, zaman serisi tahmin yöntemlerinden Gri Tahmin (GT) ve Bulanık Zaman Serisi (BZS) yöntemleri kullanarak tahmin edilmesi amaçlanmıştır. Bulanık zaman serisi yöntemi dalgacık dönüştürme tekniği ile melezleştirilmiştir. Gri tahmin modelinde ise yuvalanan GM (1 1 ) modeli oluşturulmuştur.

\section{Materyal ve Yöntem}

Bu çalışmada Toprak Mahsulleri Ofisi kurumundan temin edilen, birim alandan elde edilen buğday üretim değerleri kullanılmıştır (Anonim, 2019b). Zaman serisi değerleri 1946-2018 yıllarına ait 73 adet veriden oluşmaktadır. Kesin bir ayrıştırma oranı olmamakla birlikte en çok tercih edilen oran, literatürde yapılan çalışmalar ışığında (Sattari ve ark., 2012, 2013), buğday verim zaman serisi değerleri yaklaşık olarak \% 75'i eğitim, \% 25'i eğitim ve test olarak iki gruba ayrılmıştır. Temin edilen zaman serisi değerleri Şekil 1'de gösterilmiştir.

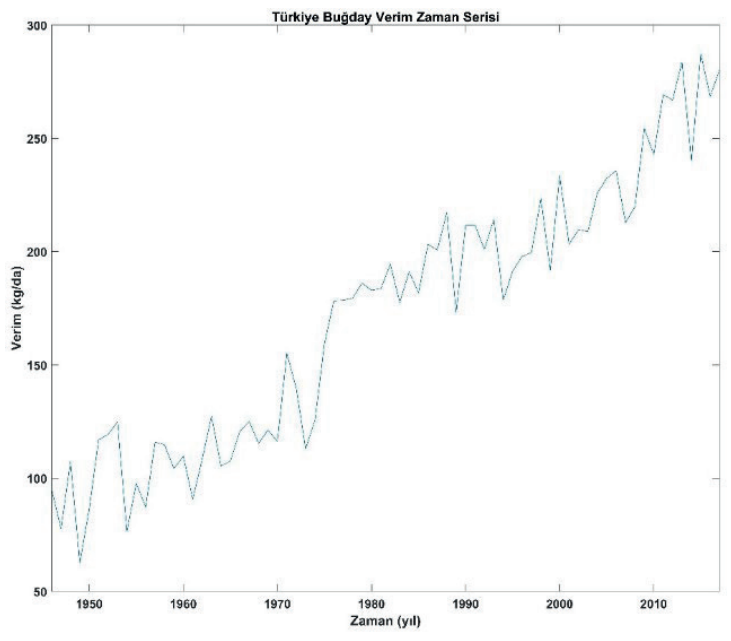

Şekil 1. Türkiye buğday verim değerleri zaman serisi grafiği 
Şekil 1'deki grafik dikkatli şekilde incelenecek olursa verim değerlerinin artış eğilimde olduğu hemen göze çarpmaktadır. Buğday verim değerlerine ait genel istatistiki bilgiler incelendiğinde; maksimum verim değerinin 2015 yılına ait $287.3 \mathrm{~kg} \mathrm{da}^{-1}$ değeri olduğu, minimum değerin ise 1949 yılına ait $62.7 \mathrm{~kg} \mathrm{da}^{-1}$ değeri olduğu görülmektedir. Verim değerleri ortalaması $171.5 \mathrm{~kg} \mathrm{da}^{-1}$, standart sapması ise $58.7 \mathrm{~kg} \mathrm{da}^{-1}$ ' dır.

\subsection{Bulanık zaman serisi (BZS)}

Bulanık zaman serisi yöntemi, doğrusal veya doğrusal olmayan tüm veri tiplerine uygulanabilen, herhangi bir önkoşulu bulunmayan tahmin yöntemidir. Temel aldığı çalışma felsefesi Zadeh (1965) tarafından geliştirilen bulanık mantığa dayanmaktadır. İlk olarak Song ve Chissom (1993) tarafından geliştirilmiştir. Bulanık mantık yaklaşımında zaman serilerinde basit ve hızlı bir şekilde karar alınmasını sağlayacak bir yaklaşımdır.

Bulanık zaman serileri tanımı: Bulanık zaman serisi çalışmalarında ilk işlem zaman serisi değerlerinin eşit aralıklara ayrıştırılmasıdır. $\mathrm{U}=\left(u_{1}, u_{2}, \ldots, u_{n}\right)$ evrensel küme olmak üzere U'nun elemanları aralıklardan oluşmaktadır. $\mathrm{Bu}$ aralıklar sabit bir aralık uzunluğunun bölümleri olarak ifade edilebilir. Aralık tanımlama işılemi Eşitlik 1'de verilmiştir.

$$
A_{j}=f_{A_{j}}\left(u_{1}\right) / u_{1}+\cdots+f_{A_{j}}\left(u_{n}\right) / u_{n}
$$

Eşitlik 1'de bulunan, $f_{A_{j}}$, $A_{j}$ bulanık kümesinin üyelik fonksiyonudur; $f_{A_{i j}}: U \rightarrow[0,1]$ olmaktadır; $f_{A_{i}},\left(u_{a}\right)$ 'nın $A_{j}$ 'ye ait olma derecesidir.

$Y(t) \in R(t=0,1,2, \ldots)$ 'nin bir zaman serisi olduğu ve $f_{i}(t)$ 'nin bu zaman serisi içerisinde bir bulanık küme olduğu varsayıldığında, $F(t)\left\{f_{i}(t), \ldots\right\}$ bir bulanık $\mathrm{Y}(\mathrm{t})$ üzerinde tanımlanmış bir zaman serisi olur. $F(t)$ 'nin yalnızca $\quad F(t-1)$ 'den etkilendiği varsayilmaktadir. $\mathrm{Bu}$ nedenle $F(t)=\mathrm{F}(\mathrm{t}-$ 1)o $R(t, t-1)$ ilişkisinde $R(t, t-1)$ e bulanık ilişki denir. Bu ilişki farklı $t_{1}$ ve $t_{2}$ değerleri için, $\mathrm{R}\left(\mathrm{t}_{1}, \mathrm{t}_{1-1}\right)=\mathrm{R}\left(\mathrm{t}_{2}, \mathrm{t}_{2-1}\right)$ ise $\mathrm{F}(\mathrm{t})$ zamandan bağımsız bulanık zaman serisi olarak; aksi takdirde zamana bağımlı bulanık zaman serisi olarak adlandırılır (Song ve Chissom, 1993).

Bulanık zaman serileri ile tahmin yapmak için izlenen genel sıra şu şekilde sıralanmaktadır:

1) Bulanık kümelerin tanımlanacağı $U$ evrensel kümesi tanımlanır.

2) U kümesi eşit uzunluktaki aralıklara bölünür.

3) Bulanık kümeler tanımlanır.

4) Bulanık ilişkiler belirlenir.

\section{5) Durulaştırma işlemi yapılır.}

Zaman serisi verilerine ait minimum ve maksimum değerler bulunarak pozitif iki sayı $\left(\mathrm{D}_{1}\right.$, $\mathrm{D}_{2}$ ) ile bir evrensel küme tanımlanır. Dmin en küçük verim değerini, Dmax ise en büyük verim değerini göstermek üzere evrensel küme $\mathrm{U}=\left[\mathrm{D}_{\min }-\mathrm{D}_{1}, \mathrm{D}_{\max }+\mathrm{D}_{2}\right]$ şeklinde tanımlanır ve daha sonra evrensel küme eşit uzunluktaki aralıklara bölünür. Aralıkları belirleme işleminin sonrasında dilsel değişkenlerin üyelik derecelerini gösteren bulanık kümeler tanımlanır. U evrensel kümesindeki bulanık kümeler Eşitlik 2'de gösterildiği gibidir (Song ve Chissom, 1993).

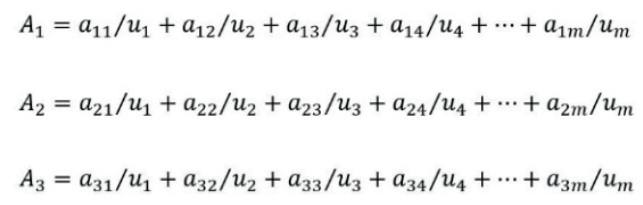

$$
A_{k}=a_{k 1} / u_{1}+a_{k 2} / u_{2}+a_{k 3} / u_{3}+a_{k 4} / u_{4}+\cdots+a_{k m} / u_{m}
$$

Eşitlik 2'de $a_{i j}, u_{j}$ aralığının $A_{i}$ bulanık kümesindeki üyelik derecesini göstermektedir.

Tanımlanan bulanık kümeler yardımıyla tahmin edilmek istenen değerin hangi bulanık kümeye düştüğü belirlenir. Son olarak bulanık küme grupları arasındaki ilişkilerden yararlanarak, tahmin edilmek istenen değer hesaplanır.

\subsection{Gri tahmin (GT)}

Gri tahmin, bilinen verilerin beyaz renkle, bilinmeyen verilerin ise siyah renkle isimlendirilmesi ve beyaz renkli veriler vasıtasıyla siyah renkli verilerin grileştirilmesini temel almaktadır (Deng, 1982). Gri tahmin modelleme işlemi 3 temel aşamaya sahiptir. $\mathrm{Bu}$ aşamalar; birikim türetme işlevi, ters birikim türetme işlevi ve gri modeldir. Gri tahmin model adımları aşağıda sıralı şekilde gösterildiği gibidir.

1. Adım: Zaman serisi değerleri $\mathrm{n}$ büyüklüğe sahip bir $X_{(0)}$ ham zaman serisi vektörü Eşitlik 3'teki gibi hesaplanmaktadır.

$$
X_{(0)}=\left(x_{(0)}(1), x_{(0)}(2), x_{(0)}(3), \ldots, x_{(0)}(n)\right) ; \quad n \geq 4
$$

2. Adım: Orijinal zaman serisi vektörüne Birikim Türetim İşlevi uygulanarak monoton artan $\mathrm{X}_{(1)}$ vektörü oluşturulur. $\mathrm{Bu}$ işleme değerlerin kümülatif olarak toplanması Eşitlik 4 ve 5'te gösterildiği şekilde yapılmaktadır. 


$$
\begin{aligned}
& X_{(1)}=\left(x_{(1)}(1), x_{(1)}(2), x_{(1)}(3), \ldots, x_{(1)}(n)\right) ; \quad n \geq 4 \\
& X_{(1)}(k)=\sum_{i=1}^{k} x_{0}(i) ; \quad(i=1,2,3, \ldots, n)
\end{aligned}
$$

3. Adım: İkinci adımda üretilen vektörden ortalama değerler türetilerek $\mathrm{Z}_{(\mathrm{i})}$ dizisi oluşturulur (Eşitlik 6 ve 7). Eşitlik 6'da bulunan ifade, Eşitlik 4 'te bulunan ve takip eden ifadelerin ortalamalarıdır.

$$
\begin{aligned}
& z_{(1)}=\left(z_{(1)}(2), z_{(1)}(3), z_{(1)}(4), \ldots, z_{(1)}(n)\right) ; \quad n \geq 4 \\
& z_{(1)}(k)=0.5_{(1)}(k)+0.5 x_{(1)}(k-1)
\end{aligned}
$$

4. Adım: $\mathrm{X}_{(0)}(\mathrm{k})+\mathrm{az}_{(1)}(\mathrm{k})=\mathrm{b}$ eşitliği ile $\mathrm{a}$ ve $\mathrm{b}$ parametreleri hesaplanır. Bu hesaplama işlemi en küçük kareler yöntemi kullanılarak yapılmaktadır.

Yukarıdaki eşitliğin matris formu yazılacak olursa $\mathrm{Y}=$ Bã eşitliği elde edilir. Burada $\mathrm{Y}, \mathrm{B}$ ve ã matrisleri ifade etmektedir (Eşitlik 8).

$$
B=\left(\begin{array}{cc}
-Z_{(1)}(2) & 1 \\
-Z_{(1)}(3) & 1 \\
-Z_{(1)}(4) & 1 \\
\ldots . & 1 \\
-Z_{(1)}(n) & 1
\end{array}\right), \quad Y=\left(\begin{array}{c}
X_{(0)}(2) \\
X_{(0)}(3) \\
X_{(0)}(4) \\
\ldots \ldots \ldots \\
X_{(0)}(n)
\end{array}\right), \quad \tilde{\mathrm{a}}=\left(\begin{array}{l}
a \\
b
\end{array}\right)
$$

ã vektörünün elde edilebilmesi için sırasıyla Eşitlik 9-11'deki işlemler gerçekleştirilmelidir.

$$
\begin{aligned}
& Y=B \tilde{a} \\
& B^{T} Y=B^{T} B \tilde{a} \\
& \tilde{a}=\left(B^{T} B\right)^{-1} B^{T} Y
\end{aligned}
$$

5. Adım: $\frac{d x_{(1)}(k)}{d k}+\operatorname{ax}_{(1)}(\mathrm{k})=\mathrm{b}$ şeklindeki diferansiyel denklem çözülmek suretiyle tahmin modeli elde edilmiş olur (Eşitlik 12).

$$
X_{(t)}(k+1)=\left[x_{(0)}(1)-\frac{b}{a}\right] e^{-a k}+\frac{b}{a}
$$

Nihai tahmin değeri için kullanılan son Gri model ise Eşitlik 13'te tanımlanmıştır.

$$
X_{(t)}(k+1)=\left[x_{(0)}(1)-\frac{b}{a}\right] e^{-a k}\left(1-e^{a}\right)^{\prime} d i r
$$

6. Adım: Nihai tahmin modeli ile tahminleme işlemi gerçekleştirilir.

\subsection{Yuvarlanan gri tahmin (YGT)}

$\mathrm{Bu}$ çalışmada belirlenen bazı " $k$ " değerleri nispetinde yuvarlanan gri model oluşturulmuştur. Örneğin, $k=4$ değeri için, ilk dört veri kullanılarak beşinci veri, iki, üç, dört ve beşinci veri kullanılarak altıncı veri tahmin edilmiştir. Eğer $\mathrm{k}=5$ olarak seçilirse ilk 5 veri ile altıncı değer, iki, üç, dört, beş ve altıncı değer kullanılarak da yedinci değer tahmin edilir (Başakın ve ark., 2019). Model oluşturma işlemi için MATLAB programından yararlanılmıştır.

\subsection{Dalgacık dönüşümü}

Zaman serileri analizlerinde, zaman bilgisine ek olarak frekans bilgisinin elde edilmesi, ayrıntılarda gizli özelliklerin görünür hale gelmesine yarar sağlamaktadır. Dalgacık dönüşümünde tüm ölçek aralığında yapılan analiz, fazla sayıda veri yığınları oluşmasına, neden olur. Bilgi yoğunluğu azaltmak amacıyla dönüşüm işleminin belirli ölçek gurupları ile yapılığı ayrık dalgacık dönüşüm analizi geliştirilmiştir. Ayrık dalgacık dönüşümü (ADD), sadeleştirmiş ayrıştırma uygulaması sayesinde işlem hacmini azaltarak gerekli sinyal bilgisini tedarik edebilmektedir (Mallat 1989). ADD, bağımsız bir dalgacık ölçeği seti (Cannas ve ark., 2006) kullanılarak dalgacık dönüşümünün basitleştirilmiş bir yaklaşımıdır. Dalgacık dönüşümüne ait detaylı bilgiye literatürdeki çalışmalardan ulaşılabilmektedir (Altunkaynak ve Özger, 2016; Altunkaynak ve Kartal, 2019). Bantlara ayırma işlemi MATLAB paket programı ile gerçekleştirilmiştir.

\subsection{Model başarı ölçütleri}

$\mathrm{Bu}$ çalışmada, tahmin modellerinin performansının değerlendirilmesinde, hata kareleri ortalaması (HKO), verimlilik katsayısı (VK) ve belirleme katsayısı $\left(\mathrm{R}^{2}\right)$ kullanılmıştır. Değerlendirmeye esas ölçütler Eşitlik 14, 15 ve 16 (a,b,c)'da verilmiştir.

$$
\begin{aligned}
& H K O=\frac{1}{n} \sum_{i=1}^{n}\left(V_{g i}-V_{t i}\right)^{2} \\
& V K=1-\left[\frac{\frac{1}{n} \sum_{i=1}^{n}\left(V_{t i}-V_{g i}\right)^{2}}{\frac{1}{n} \sum_{i=1}^{n}\left(V_{o}-V_{g i}\right)^{2}}\right] \\
& R^{2}=1-\frac{\text { Regresyon Kareler Toplaml }(R K T)}{\text { Genel Kareler Toplaml }(G K T)} \\
& R K T=\sum\left(V_{t i}-V_{o}\right)^{2} \\
& G K T=\sum\left(V_{g i}-V_{o}\right)^{2}
\end{aligned}
$$

Eşitlik 14, 15 ve 16 (a,b,c)'da VK, Verimlilik Katsayısın1; n, toplam gözlem ve tahmin değeri sayısını; $V_{\text {ti }}$, i. verim tahmin değerini; $V_{\text {gi }}$, i. gerçek verim değerini; $V_{0}$, gerçek verim değerleri ortalamasını ifade etmektedir. VK, hata karelerinin ortalaması ve gerçekleşen değerlerin varyansına 
bağlı bir parametredir. Verimlilik katsayısının 1 olması tahmin başarısının en yüksek değeri aldığını gösterir (Nash ve Sutcliffe, 1970). Bu sebeple 1'e çok yakın değerler çok başarılı model olarak adlandırılabilmektedir.

\section{Bulgular ve Tartışma}

Bu çalışmada, Türkiye'ye ait buğday verim değerlerinin tahmin edilmesi için iki farklı zaman serisi analiz yöntemi ve bir adet zaman serisi önişlem yöntemi kullanılmıştır. Bulanık zaman serisi tahmin modelleri oluşturulurken, evrensel kümenin eşit parçalara ayrılma işlemi deneme yanılma yolu ile seçilmiştir. Evrensel küme 6 ile 15 arasında değişen sayıda eşit aralıklara bölünmüş ve eğitim kümesi hata değerleri kontrol edilerek en iyi aralık sayısı 9 olarak bulunmuştur. BZS modelleri oluşturulurken tekrar eden verim değerleri meydana gelme ihtimallerine bağlı olarak hesaba katılmıştır. Yani grup işlemleri sırasında eğer $\mathrm{A}_{1}, \mathrm{~A}_{2}, \mathrm{~A}_{2}, \mathrm{~A}_{2}$, $A_{2} \rightarrow A_{3}$ ilişkisi söz konusu ise Chen (1996)'e göre $\mathrm{A}_{3}$ kümesine düşen değer için tahmin değeri $\mathrm{A}_{1}$ kümesinin orta değeri ve $\mathrm{A}_{2}$ kümesinin orta değerlerinin ortalaması şeklinde olmaktadır. $\mathrm{Bu}$ çalışmada ise $\mathrm{A}_{3}$ kümesindeki değerin tahmin değeri $\left(0.8 \mathrm{~A}_{2}+0.2 \mathrm{~A}_{1}\right) / 2$ şeklinde olmaktadır. Tekrar eden değerlerin bir sonraki verim değerinde daha çok etkili olduğu düşünülerek etkisi arttırılmıştır (Başakın, 2018). BZS modelleri için Java ortamında bir araç geliştirilmiştir. BZS modeli test kısmının VK ve HKO değerleri sirasi ile 0.75 ve 19846 olarak gerçekleşmektedir. Ayrıca Şekil 2'de BZS modeline ait saçılma grafiği verilmiştir. Grafik incelenecek olursa, mükemmel model çizgisine yakın bir saçılma olmakla birlikte, düşük verim değerlerinin olduğu kısımda tahmin değerlerinin doğruluğunun azaldığı söylenebilir.

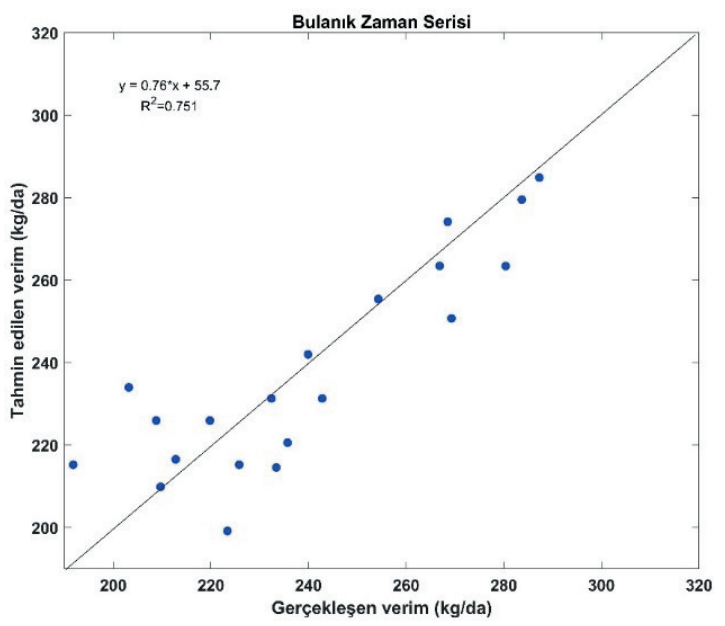

Şekil 2. Bulanık Zaman Serisi saçılma grafiği

Gri tahmin ile model oluşturma aşamasında, farklı birçok k (gecikme) değeri için tahmin modelleri oluşturulmuştur. Oluşturulan modellere ait VK ve HKO değerleri Tablo 1'de verilmiştir. Monoton artan veya azalan olmayan modellerde, YGT modelinin uygun olduğuna literatür incelemesi sonucunda ulaşılmıştır (Başakın ve ark.,

Tablo 1. Gecikme değerleri ve YGT model başarıları

\begin{tabular}{|c|c|c|c|c|c|c|c|c|c|c|}
\hline \multirow{2}{*}{ Ölçüt } & \multicolumn{10}{|c|}{$\mathrm{k}$ değeri } \\
\hline & 4 & 5 & 6 & 7 & 8 & 9 & 10 & 11 & 12 & 13 \\
\hline $\mathrm{HKO}$ & 69347 & 62580 & 53041 & 48788 & 47441 & 41175 & 37414 & 34987 & 33724 & 34256 \\
\hline VK & 0.16 & 0.24 & 0.35 & 0.40 & 0.42 & 0.5 & 0.54 & 0.57 & 0.59 & 0.58 \\
\hline
\end{tabular}

2019). Modeller $\mathrm{k}=4$ değerinden başlanarak $\mathrm{k}=13$ değerine kadar oluşturulmuştur. Model tahmin hatalarının 12. gecikme değerinden $(\mathrm{k}=12)$ sonra azalma eğilimi gösterdiği görülmüştür. En yüksek VK (0.59) ve en düşük HKO (33724) değerine sahip YGT modelinin 12 gecikme değeri ile kurulan model olduğu belirlenmiştir (Tablo 1). YGT modeline ait saçılma grafiği Şekil 3'te gösterilmiştir. Grafik incelendiğinde YGT modelinin çok iyi bir performans sergilediği söylenemez. Tahmin değerleri mükemmel model çizgisine çok yakın bir saçılma sergilememektedir.

Zaman serisi önişleme yöntemlerinden olan dalgacık dönüşümü (DD) uygulanan veriler ile oluşturulan dalgacık bulanık zaman serisi (DBZS) modeli, çalışmadaki en yüksek VK ve en düşük HKO değerine sahip model olmuştur. Model

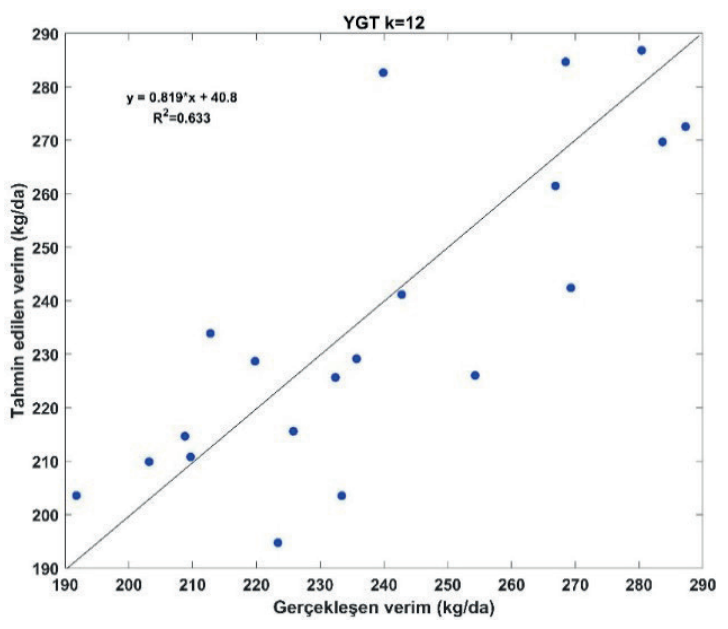

Şekil 3. Yuvarlanan Gri Model saçılma grafiği 
kurulum aşamasında orijinal verim zaman serisi değerleri ayrık dalgacık dönüşümü ile farklı frekansta 5 banda ayrılmıştır. Bantlardan 4'ü detayları içeren, biri ise detaylardan arındırılmış orijinal zaman serisine en yakın gidişata sahip olan "yaklaşım” bandıdır. Tüm bantlar kendi içerisinde eğitim ve test bölümlerine ayrıştırılıp, daha sonra test kısmındaki tahmin değerleri toplanmıştır. Tüm bantlardan elde edilen tahmin değerlerinin toplanması ile elde edilen nihai tahmin değerleri olmuştur. Dalgacık dönüşümlü model ile trend, mevsimsellik ve gürültü ögelerinin etkisinden arındırılarak daha sağlıklı bir tahmin modeli oluşturulmasına olanak sağlamıştır. DBZS ait saçılma grafiği Şekil 4'te verilmiştir.

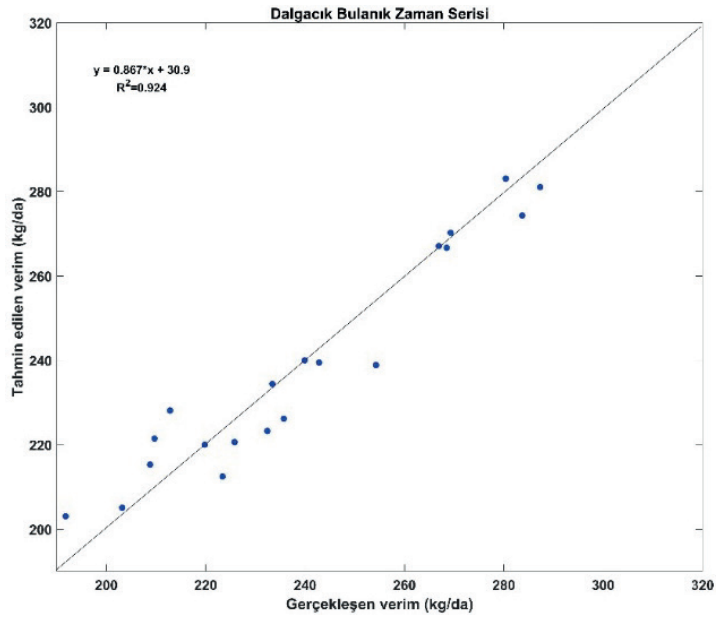

Şekil 4. Dalgacık BZS saçılma grafiği

Grafik incelendiğinde tüm tahmin değerlerinin neredeyse mükemmel model çizgisi üzerinde saçıldığ1 gözlemlenebilmektedir (Şekil 4). Bu modelde de düşük verim değerlerinin tahmini bir miktar hata içermektedir. Ayrıca tüm modellere ait tahmin zaman serileri, gerçekleşen değerler ile aynı anda mukayese edilmesi açısından Şekil 5'te birlikte verilmiştir. Grafik incelendiğinde en iyi uyuma sahip modelin DBZS modelinin en kötü uyuma sahip modelin ise YGT modelinin olduğu açıkça gözlemlenebilmektedir (Şekil 5). Tüm yöntemlere ait performans değerleri Tablo 2'de verilmiştir. Tablo 2 incelendiğinde, BZS modeli VK değeri kabul edilebilir seviyede ve 0.75 olarak hesaplanmıştır. İkinci model olan YGT modeli VK sonucu ise 0.59 ile vasat sayılabilecek bir performans sergilemiştir. DBZS yöntemine ait VK değeri 0.92 ile en başarılı model özelliği göstermektedir.

Literatürde gerçekleşen ve tahmin edilen değerlerin aynı dağılımdan gelip gelmediğinin test edildiği çalışmalar da mevcuttur (Sattari ve ark., 2012). Çalışmada gerçekleşen ve tahmin edilen değerlerin aynı dağılımdan gelip gelmediği test edilmiştir. Test işlemi için parametrik olmayan Kruskal-Wallis testi kullanılmıştır. Test işlemi SPSS paket programı yardımıla gerçekleştirilmiştir. $\mathrm{Bu}$ test normallik ve homojenlik varsayımları olamadan çalışabilmektedir. $\mathrm{Bu}$ test sonucunda üç tahmin modelinin tahmin sonuçları ve gerçekleşen değerler karşılaştırılmıştır. Belirlenen güven aralığında (\% 95) tüm modellerin olasıllk (p) değerleri 0.05 den büyük çıkmıştır. " $\mathrm{H}_{0}=$ Karşılaştırılan gruplar arasında anlamlı fark yoktur." Yokluk hipotezi ret edilmemiştir. Modellere ait p değerleri; DBZS, BZS ve YGT için sırasıyla $0.892,0.850$ ve 0.957 olarak ölçülmüştür. $\mathrm{Bu}$ değerler ile kurulan modellerin tahmin için istatistiksel olarak anlamlı olduğu sonucuna varılmıştır.

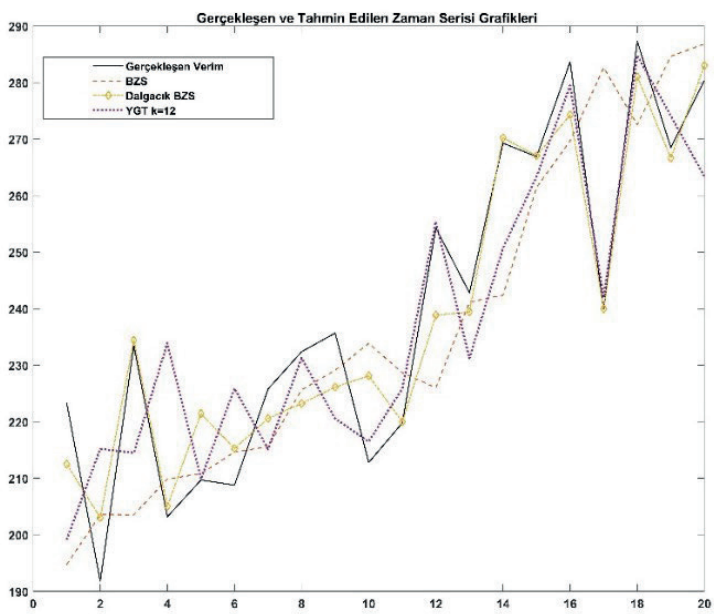

Şekil 5. Gerçekleşen verim değerleri ve tüm modellere ait tahmin edilen değerler

Tablo 2. Test kısmı model performans değerleri

\begin{tabular}{cccc}
\hline Ölçüt & BZS & YGT $(\mathrm{k}=12)$ & DBZS \\
\hline HKO & 19846 & 33724 & 6273 \\
VK & 0.75 & 0.59 & 0.92 \\
R $^{2}$ & 0.75 & 0.63 & 0.92 \\
\hline
\end{tabular}

\section{Sonuçlar}

Bu çalışmada, Türkiye buğday verim değerlerinin tahmin edilmesi amaciyla zaman serisi tahmin yöntemlerinden faydalanılmıştır. Gelecekte gerçekleşebilecek verim değerlerinin tahmin edilmesi açısından çalışmanın literatürde önemli bir yer edineceği düşünülmektedir. Türkiye'de yapılan diğer çalışmalarla karşılaştırıldığında bu çalışma, eğitilen modellerin gerçekleşen değerler ile test edilmesi açısından öne çıkmaktadır. Ayrıca son zamanlarda kullanım sayısı giderek artan, basit ve anlaşılır bir model olan BZS yönteminin ziraat alanında ilk kez kullanımı gerçekleştirilmişstir. BZS yöntemi hem tek başına hem de dalgacık dönüşümü ile birlikte kullanılmıştır. Melez model olan DBZS, tahmin değerlerinde büyük oranda iyileştirme 
sağlamıştır. Çalışma istatistiksel başarı ölçütleri ile analiz edildiğinde, DBZS modelleri ile gayet başarılı sonuçların alındığını göstermektedir. Karar alıcı mercilerin hızlı aksiyon alabilmeleri açısından, her kesimden araştırmacının kolaylıkla kullanabileceği modellerin oluşturulması gerçekleştirilmiştir. Zaman serisi değerlerinin, verim değerini etkileyen tüm değişkenlerin etkisi altında olduğu bilinmektedir. Yani yağış, sıcaklık, toprak nemi vb. parametrelerin verimi etkilediği bilinmektedir ve zaman serisi değerleri bu etkileri de içinde gömülü olarak barındırmaktadır. Fakat tahmin değerlerinin daha isabetli tahmin edilebilmesi için birçok bağımsı değişken ile yeni tahmin modellerinin oluşturulması da düşünülmelidir. Bu yönüyle çalışma geliştirilmeye muhtaç konumdadır.

\section{Kaynaklar}

Akın, M., Eyduran, S., 2017. Zaman serisi analiz yöntemlerini kullanarak 2016-2025 dönemi Türkiye avokado üretiminin belirlenmesi. Yüzüncü Yll Üniversitesi Tarm Bilimleri Dergisi, 27(2): 252258.

Altilar, D.T., Terliksiz, A.S., 2018. Comparison of statistical methods for predicting wheat yield trends in Turkey. 7th International Conference on AgroGeoinformatics (Agro-geoinformatics), 6-9 August, Hangzhou, pp. 1-4.

Altunkaynak, A., Kartal, E., 2019. Performance comparison of continuous Wavelet-Fuzzy and discrete Wavelet-Fuzzy models for water level predictions at northern and southern boundary of Bosphorus. Ocean Engineering, 186: 106097.

Altunkaynak, A., Özger, M., 2016. Comparison of discrete and continuous wavelet -multilayer perceptron methods for daily precipitation prediction. Journal of Hydrologic Engineering, 21(7): 04016014.

Anonim, 2019a. Bitkisel Üretim İstatistikleri. Türkiye İstatistik Kurumu, (http://www.tuik.gov.tr/Veri Bilgi.do?alt_id=45), (Erişim tarihi: 10.12.2019).

Anonim, 2019b. Bitkisel Üretim İstatistikleri. Türkiye İstatistik Kurumu, (http://www.tmo.gov.tr/Main. aspx?ID=40), (Erişim tarihi: 10.12.2019).
Başakın, E.E., 2018. Dalgacık bulanık zaman serisi yöntemi ile aylık akım tahmini. Yüksek Lisans Tezi, İstanbul Teknik Üniversitesi, Fen Bilimleri Enstitüsü, İstanbul.

Başakın, E.E., Özger, M., Ünal, N., 2019. Gri tahmin yöntemi ile İstanbul su tüketiminin modellenmesi. Politeknik Dergisi, 22(3): 755-761.

Berk, A., Uçum, İ., 2019. Türkiye'nin nohut üretiminin ARIMA modeli ile tahmini. Journal of the Institute of Science and Technology, 9(4): 2284-2293.

Cannas, B., Fanni, A., Sias, G., Tronci, S., Zedda, M.K., 2006. River flow forecasting using neural networks and wavelet analysis. Geophysical Research Abstracts, 7: 214-219.

Chen, S.M., 1996. Forecasting enrollments based on fuzzy time series. Fuzzy Sets and Systems, 81(3): 311-319.

Deng, J.L., 1982. Control problems of grey systems. Systems \& Control Letters, 1(5): 288-294.

Mallat, S.G., 1989. A theory for multiresolution signal decomposition: The wavelet representation. IEEE Transactions on Pattern Analysis and Machine Intelligence, 11(7): 674-693.

Nash, J.E., Sutcliffe, J.V., 1970. River flow forecasting through conceptual models part I-A discussion of principles. Journal of Hydrology, 10(3): 282-290.

Özer, O., İlkdoğan, U., 2013. Box-Jenkins modeli yardımıyla dünya pamuk fiyatının tahmini. Tekirda $\breve{g}$ Ziraat Fakültesi Dergisi, 10(2): 13-20.

Sattari, M.T., Pal, M., Yürekli, K., Ünlükara, A., 2013. M5 model trees and neural network based modelling of $\mathrm{ET}_{0}$ in Ankara, Turkey. Turkish Journal of Engineering and Environmental Sciences, 37: 211219.

Sattari, M.T., Yurekli, K., Pal, M., 2012. Performance evaluation of artificial neural network approaches in forecasting reservoir inflow. Applied Mathematical Modelling, 36(6): 2649-2657.

Song, Q., Chissom, B.S., 1993. Fuzzy time series and its models. Fuzzy Sets and Systems, 54(3): 269-277.

Yıldız, M., Atış, E., 2019. Türkiye organik incir ihraç fiyatının arma yöntemi ile tahmini. Tarım Ekonomisi Dergisi, 25(2): 141-147.

Zadeh, L.A., 1965. Fuzzy sets. Information and Control, 8(3): 338-353. 